\title{
Image Digitizer
}

\section{Pierre A. Magnien}

Association Astronomique de France-Comté, 34, av. de l'Observatoire, F-25000 Besançon, France

Abstract. Equipment for digitizing $24 \times 36 \mathrm{~mm}$ negatives was described. The sensing unit is a 1024-element CCD. Apart from the optical train, the transparency is held in a rigid carrier that is moved by a stepper motor to scan one row at a time. The whole operation is controlled by computer, and results in a $170.5 \mathrm{~kb}$ file for each image.

\section{"Comet" Software}

\section{P. Butzbach and J.P. Parisot}

Association Astronomique de France-Comté, 34, av. de l'Observatoire, F-25000 Besançon, France

\begin{abstract}
A suite of programs written in BASIC for use on Apple (II, IIe, etc.) computers was described. A data file, extracted from the general catalogue by Marsden is incorporated. The programs are applicable to any geographical location and allow the determination of positions (in both celestial and horizontal coordinates), times of rising, transit and setting, and the calculation of ephemerides from orbital elements.

Dumoulin, C.: La Gazette d'Uranie, Hors-Série No.1, Groupe de Recherche et d'Animation en Astronomie du Limousin, IREM de Limoges, 1986

Dumoulin, C., Parisot, J.P.: Astronomie pratique et informatique, Masson, Paris, 1987

Marsden, B.: Catalogue of cometary orbits, I.A.U., 1982

Meeus, J.: Astronomical formulae for calculators, Willmann-Bell, 1982
\end{abstract}

\section{Refining the Orbit of Visual Double Stars}

\section{Edgar Soulie}

"Les Dryades", 19, av. Salengro, F-92290 Chatenay-Malabry, France

Abstract. An iterative method of refining the orbital parameters of visual double stars was described. The sum of the least-square differences is minimized by the Levenberg-Marquardt method. The application to two examples was described, including one highly inclined orbit, ADS 8862=Hussey 664 ( $i=94.3$ degrees).

Marquardt, D.W.: “An algorithm for least-squares estimation of non-linear parameters", $J$. Soc. Industr. Appl. Math., 11 (2) 431-41, 1963 June

Soulié, E.J.: "L'amélioration de l'orbite d'une étoil double visuelle", Astron. Astrophys., 164, 408-14, 1986

Soulié, E.J.: Special Issue "Double Stars", l'Astronomie, 1988, in press 